ADLFI. Archéologie de la France -

Informations

une revue Gallia

Normandie | 2009

\title{
Canton de Falaise nord
}

\section{Yves Hamonou}

URL : https://journals.openedition.org/adlfi/3971

ISSN : 2114-0502

Éditeur

Ministère de la Culture

Référence électronique

Yves Hamonou, «Canton de Falaise nord » [notice archéologique], ADLFI. Archéologie de la FranceInformations [En ligne], Normandie, mis en ligne le 01 mars 2009, consulté le 22 juin 2021. URL : http:// journals.openedition.org/adlfi/3971

Ce document a été généré automatiquement le 22 juin 2021.

(c) ministère de la Culture et de la Communication, CNRS 


\title{
Canton de Falaise nord
}

\author{
Yves Hamonou
}

Date de l'opération : 2009 (PI)

1 Dans le cadre d'une étude sur le choix de certaines séries microtoponymiques comme indicateur pouvant révéler une présence éventuelle d'une occupation humaine, une campagne de prospection a été menée sur des parcelles de certaines communes du canton au cours de l'automne 2009. Si la prospection pédestre s'est avérée infructueuse sur certaines d'entre elles (peu d'indices révélateurs, champs en herbages), elle a cependant permis d'identifier la présence de quelques sites d'époque gallo-romaine et aussi de localiser des découvertes anciennes dont certaines ont été faites au XIX ${ }^{\mathrm{e}} \mathrm{s}$.

2 La prospection a permis de localiser deux sites gallo-romains, l'un à Bons-Tassilly, aux lieux-dits «La Pierre Sollier » et «La Robillarde» et un autre à Ussy, au lieu-dit «Le Champ Saint-Pierre », à proximité duquel un lot de trois monnaies gauloises a été recueilli. Deux des monnaies ont pu être identifiées. Il s'agit de statères (type « aux sangliers et au profil de style figuratif »), datant des II ${ }^{\mathrm{e}}$ s. av. J.-C. et I ${ }^{\mathrm{er}}$ s. av. J.-C. Deux enceintes ont été reconnues, l'une à Villers-Canivet, dans le Bois Royal de Villers dénommé «L'Ermitage » où de la céramique commune gallo-romaine a été recueillie, l'autre à Martigny-sur-l'Ante, dans l'ancien bois de "Marcrue", aujourd'hui en herbage, découverte signalée lors du défrichement du bois en 1839 .

Elle a également permis de localiser plus précisément sur Villers-Canivet la découverte gallo-romaine signalée près du hameau du Bas de la Grurie, et qui se situe au lieu-dit "Les Brévinières", ainsi que d'identifier un site à Cordey, au lieu-dit "Le Parc" (habitat médiéval ou moderne?). 


\section{AUTEURS}

YVES HAMONOU

BEN 